\title{
Possible Health Danger Associated With Gabbage/Refuse Collectors
}

\author{
Sani Mohammed and Assoc. Prof. Dr. Puziah Abdul Latif \\ Faculty of Environmental studies, Universiti Putra Malaysia,43400 UPM Serdang, Selangor, Malaysia.
}

\begin{abstract}
Wastes collectors refer to groupof people who collects solid waste generated in various areas for disposal at designated locations. The service is usuallyprovided by responsible contractors assigned to schedule areas. In advanced nations such as Europe and the USA, automated trucks are used in collection and disposal of waste using hydraulic lifts. The opposite is applied in developing countries such as Malaysia. Wastes collectors in the study area are manually collecting the waste before lifting it on the operational trucks. Manual waste collection service is associated with health danger. The workers are exposed to odors, and they can dirty their cloths easily as result of non-usage of protective gears. Other health danger includes injuries from broken glasses, musculoskeletal disorder and diseases that accompany solid waste. The aim of this project was to determine whether the workers are exposed to the work practices, injuries, musculoskeletal disorder and other danger faced by Malaysian refused collectors in carrying out their responsibilities. The sample for the study constituted thirty (30) solid waste collectors selected through convenient sampling technique. Data for the study was collected through a structured questionnaire on Malaysian refused collectors and visual observation. Responses were analyzed using descriptive statistics. Results revealed that out of the total respondents $56.6 \%$ disagreed and strongly disagreed that collectors always make use of their protective material at work, $10 \%$ were neutral while 33.3\% agreed and strongly agreed. This implied that majority of the collectors have no access to personal protective equipment which is contrary to OSHA requirements. The study therefore concludes that solid waste collectors experienced different types of preventable dangers inherent in their duty due to their work practice.
\end{abstract}

Keywords: Garbage/refuse collector, personal protective equipment, musculoskeletal disorder, Seri kembangan metropolis, Selangor, Malaysia.

\section{Introduction}

Municipal solid waste (MSW) consists of disused items that are discarded by people. Section of the solid waste generated by a family is called refuse, which includes left-over food, broken glass, empty cans, scrap papers, and other spoiled goods. Trash could be seen as larger things such as tree limbs and timewornutilities that are usually not deposited into a garbage can (Lincoln, J. 1996). Waste is defined asmaterials without economic value and the owner, as of the time of disposal, is willing to discard the properties that could be seen as waste. Meanwhile, waste generation, collection and handling methods are of greater concern to the present study.

Waste handling is associated with various adverse effectsbecause of the way and manner by which waste collectors perform their duty with its perceived negative health impacts associated with improper handling of such waste. This has remained a source of concern to many local authorities and researchers alike.

The responsibilities of solid waste collectors include emptying of refuse containers into a truck using eitherhydraulic lift or their physical strength and describing the criterions for appropriate disposal to customers (California occupational guide, 2002). But for the purpose of this work, municipal waste was the concern because of its volume and diversity. Meanwhile, clinical wastes are beyond the scope of this work. The type and collection of solid waste would thereby be to study health related hazards associated with solid waste handling.

Collection containers could either beplastic bags or paper bags, bins and drums to two wheeled or four wheeled containers (Poulsen and Breum, 1995). However, solid waste collection has become a very difficult and complex task in our urban areas since the generation of neighborhood and restaurants, and other solid waste generators takes place continuously.

It necessitatesrecurrentweighty physical activity like lifting of heavy containers (Ray et al., 2005). Despite the importance of this job, waste collectors face a lot of hazards in the course of discharging their duties.

Thedangers include wounds from sharp items like broken glass, notched edges of cans, and knives bulging as gears are raised or swayed (Kuijer and Frings-Dresen, 2004).Unintentional injuries such as puncture wounds, abrasions, lacerations, dog bites, burns and rat bites are very common injuries among waste collectors, as are serious cuts caused by torn metal, cans and broken glass or protruding nails in discarded refuse. Other injuries occur when refuse collectors drop heavy containers on their feet or legs (Lincoln, 1996). 
Therefore, the type of activities required in refuse collection involved the use of protective gears. They works in high traffic routes and also convey heavy loads, the safety gears they require include foot wear, nose masks, high visibility clothing capable of being seen by car drivers from a reasonable distance, gloves, weatherproof clothing and reinforced trousers to minimize against punctured wounds from sharp objects. The protective equipment should be suitable to the tasks; where possible the personal protective equipment should be tried out before general use (California occupational guide, 2002).

It shall be the responsibility of every waste collection worker to wear protective gears while at work, and work uniform provided by employers for sake of safeguarding the health of workers, and for proper recognition (Malaysian OSHA, 2006). This project focuseson exploring and determining the work practice and danger that refuse collectors are vulnerable to while carrying out their responsibilitiesfollowed by suitable recommendations.

\section{Literature Review}

A work that has contributed significantly to healthy living by curving the danger of various diseases like water borne diseases and cholera is proper handling of waste (Kuijer et al., 2010). There are number of diseases that are closely related with improper waste collection (Wouters et al., 2002).

Standard operation procedures in managing municipal solid wastes in developed nations have greatly limits various hazards associated with pollution considerably. However, such dangers are still prevalent in developing nations as a result of poor occupational safety practice in waste collection. In low-income countries, solid waste collectors have low socio-economic status such as poverty, lack of education, poor housing conditions and poor nutrition, furthermore, this group of workers are exposed directly and without adequate personal protection to municipal solid waste (MSW) which includes hazardous substances (Sabde\&Zodpey, 2008).

In many third world countries, MSW is done manually and household waste removal is work that requires physical strength in lifting bulky waste containers, and common complaints among refuse collectors are increased risk of musculoskeletal disorders, the lower back being the most affected body region. Others frequently affected areas are shoulders, knees, and neck (Yang et al., 2001).

Waste collection requires physical strength, which is related tonumerous risk of musculoskeletal disorders (MSDs) (Ijzelenberg et al., 2004). Taiwan refuse collectors were found to complain of musculoskeletal injuries of lower back, wrist, and elbow. The prevalence of injuries in waste collection work was more than doubling the office workers (Yang et al., 2001).

During refuse collection, the most vulnerable body parts most were the back, arms, and legs. The frequent complain were strains/sprains, cutting injury, laceration, twisting and soft tissue injury, cause by either falls or slip injuries, being hit or injured by sharp object, cut by broken glass, or piercing object and straining of the body (Kuijer\&Frings-Dresen, 2004)

In order to work, especially at physically demanding jobs such as solid waste collection, the worker must be relatively healthy. In this environment, the workers' health is his/her greatest asset and a precondition for the sustainable generation of income. Protection of workers from occupational hazards depend on availability and proper utilization of protective equipment, which in low and middle income countries is in short supply with very limited monitoring of their utilization (Merson et al.,2001). Moreover, refuse workers often lack training, tools and information in order to perform their work in the best healthy and safe manner. In addition to these, routine medical checkup program for all solid waste collectors should be mandatory to keep them in good health condition. (Tiwari, 2008).

The exposure to certain physically related injuries and musculoskeletal disorders such as puncture wounds, laceration, serious cuts, dislocation, body pain and fatigue associated with the refuse collectors not using personal protective equipment and carrying heavy materials affects the health status of workers and consequently reduces the manpower, increases cost of collection and is a possible cause of death.

The overall objective is to assess the danger associated with refuse collection and its associated health impact. However, the specific objectives are:

1. To evaluate the compliance of the OSHA 2006 by refuse collection companies

2. To assess health related impact associated with refuse collection activities

3. To understand the extent to which the employers and employees are committed to safety and health practices at work place

\section{Materials And Methods}

The study area Seri Kembangan, previouslyidentified as Serdang new village, is a municipalitysituated in Selangor, Malaysia. The municipality has grown to sizeable size, having more than 2,500 houses such as lowrise detached dwellings, medium-rise apartments, high-rise apartments and commercial/industrial facilities with a population of more than 150,000 , mainly made up of entrepreneurs, businessmen, professionals, and 
government servants that work in Putrajaya and other multinational corporation's employees located in Cyberjaya.

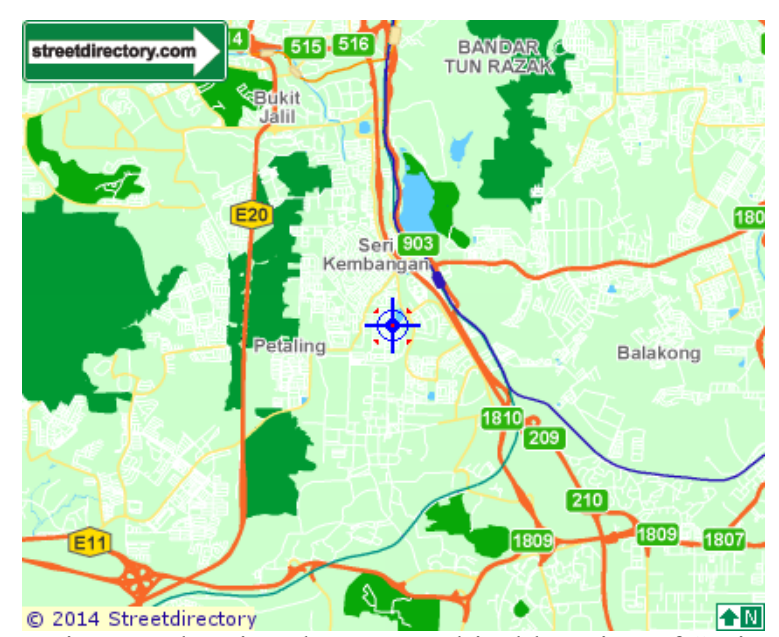

Fig.1 Schematic map showing the geographical location of Seri Kembangan

\subsection{Study Design}

The study was conducted using a questionnaire survey of refuse collectors in Seri Kembangan with a sample size of thirty respondents. Twenty-five of the refuse collectors are fromMewah Yusuf enterprise, a private company contracted by MajlisPerbandaranSubang Jaya (MPSJ). While the remaining five respondents are refuse collectors from Putrajaya. Outstandingauthorization was gotten from the supervisors to include theiremployees' in this research. All respondent's participated voluntarily. Privacy of the respondents was guaranteed to boost the assuranceofthe participants'in giving out the requested information.

Data for the study was collected through structured questionnaire on refuse collectors and pictures taken at the site during collection. Physical observations of the components of the solid wastes were also carried out on every site visited. Questionnaires were completed with responses from the respondents by a trained Bangladeshi who read the questions in simplified language to the respondents; this was to enhance accuracy of the contents of the designed question asked in the questionnaire. The refuse collectors were always met on duty at their various sites with the help of their supervisor throughout the period of data collection. The period of data collection was two weeks.

The first part of the questionnaire was designed to elicit socio-demographic information while the second part was to elicit information on their knowledge on current work practice, awareness level on personal protective equipment, most prevalent musculoskeletal disorders and most prevalent injuries. The completed questionnaires were sorted, collated and analyzed using descriptive statistics.

Both qualitative and quantitative data were integrated into the analysis. The qualitative data analysis involved the transcription of the information from pictures. The results of the qualitative data were used in the explanation of some of the findings of the study.

\section{Results And Discussion}

Respondents were all males and their age ranged between 15 to 45 years. Twenty three percent of the respondents were between the age ranges of $15-25$ years. $50 \%$ were between $26-35$ of age while $27 \%$ were between 36-45 years and none were above 45 years, so the study revealed that the majority of the workers are within their productive years as shown in Table 1 below. This corroborates the submission of Inyang M. (2007). Those workers within the age of 15 to 35 are still in their productive years and thus required reasonable protection against the associated hazards inherent in solid waste so that their future will not be marred.

Table 1: Age of respondents.

\begin{tabular}{|l|l|l|}
\hline & No. of respondents & Percentage (\%) \\
\hline $15-25$ & 7 & 23 \\
\hline $26-35$ & 15 & 50 \\
\hline $36-45$ & 8 & 27 \\
\hline $45-$ Above & None & None \\
\hline Total & 30 & 100 \\
\hline
\end{tabular}


Table 2: Educational qualifications of respondents.

\begin{tabular}{|l|l|l|}
\hline $\begin{array}{l}\text { Educational } \\
\text { qualification }\end{array}$ & $\begin{array}{l}\text { No. of } \\
\text { respondents }\end{array}$ & $\begin{array}{l}\text { Percentage } \\
(\%)\end{array}$ \\
\hline No formal & 15 & 50 \\
\hline Primary & 10 & 33.3 \\
\hline Secondary & 5 & 16.6 \\
\hline Total & 30 & 100 \\
\hline
\end{tabular}

The respondent's whose last educational qualification as of the time of conducting the survey is primary education certificate was $33.3 \%$. While $16.6 \%$ of the respondent had secondary school certificate, and $50 \%$ of the respondents had never gone to school as shown on Table 2 above. Most of those who had secondary education might not have wanted to identify with this type of job as it is considered a dirty job and this might not be unconnected with the fact that members of the public look down on solid waste collectors, just as revealed by Inyang M. (2007) that most of the waste collectors admitted doing the job was a last resort in the absence of a better alternative. $33.3 \%$ of the respondentswere not married while $66.6 \%$ were married as shown in Table 3 below. Thus reiterating the need to put in place a system that will minimize the danger inherent in waste collection, this is necessary to enhance the health of the workers to cater for their families and also serve the public.

Table 3: Marital status of respondents.

\begin{tabular}{|l|l|l|}
\hline \multicolumn{1}{|c|}{ Marital Status } & \\
& No. of respondent & Percentage (\%) \\
\hline Single & 10 & 33.3 \\
\hline Married & 20 & 66.6 \\
\hline Total & 30 & 100 \\
\hline
\end{tabular}

All of the respondents are foreigners as shown on Table 4 and this may be in connection with the nature of the job and their poor background coming from low-income countries as ascertained by Sabde and Zodpey, (2008) that solid waste collectors have low socio-economic status such as poverty, lack of education, poor housing conditions and poor nutrition

Table 4: Races of the respondents.

\begin{tabular}{|l|l|l|}
\hline \multicolumn{1}{|c|}{ Race } & $\begin{array}{l}\text { No. of } \\
\text { respondents }\end{array}$ & $\begin{array}{l}\text { Percentage } \\
(\%)\end{array}$ \\
\hline Malay & Nil & Nil \\
\hline Chinese & Nil & Nil \\
\hline India & Nil & Nil \\
\hline Other foreigners & 30 & 100 \\
\hline Total & 30 & 100 \\
\hline
\end{tabular}

Table 5: Responses of respondent on current work practice expressed in percentage (\%)

\begin{tabular}{|c|c|c|c|c|c|c|}
\hline Knowledge on current work practices & $\mathrm{S} / \mathrm{A}$ & $\mathrm{A}$ & $\mathrm{N}$ & $\mathrm{D}$ & $\mathrm{S} / \mathrm{D}$ & $\begin{array}{l}\text { Total } \\
(\%)\end{array}$ \\
\hline $\begin{array}{l}\text { Refuse are emptied into the truck with } \\
\text { hydraulic lifts }\end{array}$ & 13.3 & 23.3 & 16.7 & 33.3 & 13.3 & 100 \\
\hline $\begin{array}{l}\text { Refuse are emptied manually with } \\
\text { physical strength }\end{array}$ & 16.7 & 40.0 & 10.0 & 16.7 & 16.7 & 100 \\
\hline $\begin{array}{l}\text { Standard of proper disposal are } \\
\text { described to customers }\end{array}$ & 16.7 & 36.7 & 13.3 & 3.3 & 30.0 & 100 \\
\hline $\begin{array}{l}\text { Overflowing containers are tagged to } \\
\text { indicated rejection of more waste to } \\
\text { members of public }\end{array}$ & 6.7 & 30.0 & 6.7 & 50.0 & 6.7 & 100 \\
\hline
\end{tabular}

*S/A-Strongly agree A-Agree N-Neutral D-Disagree $\quad \mathrm{S} / \mathrm{D}$-Strongly Disagree

$13.3 \%$ of respondents strongly disagree that refuse are emptied into truck with hydraulic lifts while $33.3 \%$ disagree. Thus, $46.60 \%$ disagree that refuse collection are performed entirely with hydraulic lifts which shows that indeed refuse in the study area are evacuated manually with their bare hands most times as shown in picture 2. Thus, exposes the waste collectors' to injuries from various dangerous components, such as broken bottles, plates, empty tins, and sharp objects. This affirmed the relationship between the method of waste collection and the resultant danger. Collection of waste with bare hand is contrary to Malaysian OSHA, 2006.

$16.7 \%$ of the respondents strongly disagree that refuse is emptied manually with physical strength another $16.7 \%$ disagree and $10 \%$ are neutral while $40 \%$ agree and $16.7 \%$ strongly agree to it. The answers given to the above two questions are consistent to each other, which indicated good understanding of the question 
asked. This is because in both low-rise detached dwellings and medium-rise apartment the common type of collection service are either curb side, set out- set back, and set outwere the containers or plastic bags are emptied manually by the refuse collectors who loaded the waste from the designated point outside the house to the collection vehicle manually (shown in pic $2 \& 3$ ) and this is in line with the assertion of Yang et al.(2001), that waste collection requires repeated heavy physical activity, such as lifting, carrying, pulling and pushing. $30 \%$ of the respondents strongly disagree that the standard of proper disposal is described to customers while $3.3 \%$ disagree. The cumulative percentage of respondents that disagreed that the standard of proper disposal is described to customer is $33.3 \%$. While $13.3 \%$ are neutral and $36.7 \%$ agree and $16.7 \%$ strongly agree bringing the total percentage of those that strongly agree and agree to $53.4 \%$. Though those that agree said so because they meet some of the waste properly disposed since it is not the duty of waste collector to enlighten the public on the proper way of waste disposal in Malaysia, which is contrary to California occupational guide, 2002. That stated the duties of waste collectors which include emptying of refuse bins into the truck using hydraulic lift or their physical strength and describing the standards for proper disposal to customers.

$6.7 \%$ of the respondents strongly agreed that overflowing containers are tagged to indicate rejection of more waste to members of the public, $30 \%$ agree while $6.7 \%$ are neutral and $50 \%$ disagree while $6.7 \%$ strongly disagree. Thus, overflowing containers were not tagged to indicate rejection of more waste to members of the public (see Figure 1 of overflow waste container). Members of the public exhibited nonchalant attitude towards the way they dumped their refuse. This corroborates the submission of Kuijer\&Frings-Dresen(2004). The negative attitude could be attributed to an erroneous belief that the council tax they pay should take care of that irrespective of how they do it (Kuijer\&Frings-Dresen, 2004).

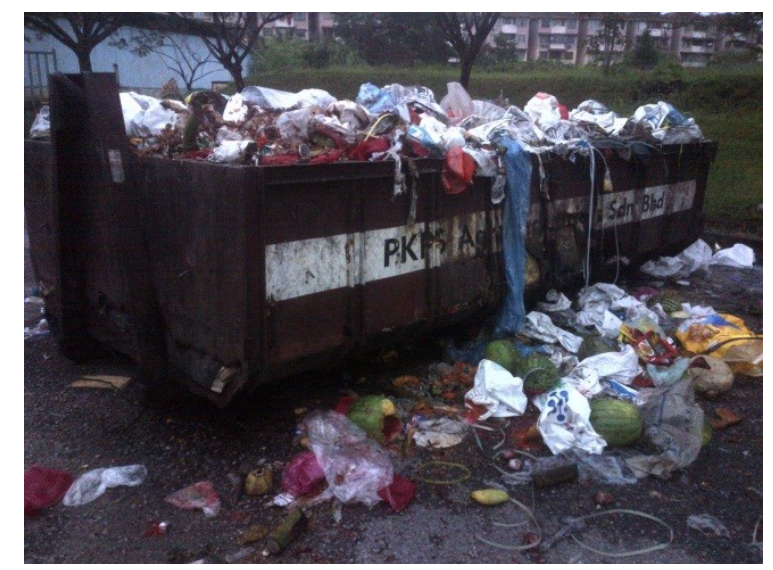

Figure 1: Showing overflowing waste container

$6.7 \%$ of the respondents strongly agree that enough hand gloves are provided for all workers and another $6.7 \%$ agree. Meanwhile, only $13.4 \%$ of respondents agreed that hand gloves, which are regarded as essential equipment for carrying out waste collection, was in short supply. $10 \%$ are neutral, $66.7 \%$ disagree, and $10 \%$ strongly disagree. In contrast to the respondents that agreed, $76.7 \%$ did not agree that hand glovesare adequately distributed amongst the respondents. This statistics revealed that waste collectors are left without the proper essential instruments to discharge their duties in a sanitary manner by exposing them to injuries from broken glasses, bottles, serrated edges of tin and other sharp components hidden in the solid waste which is contrary to Malaysian OSHA, 2006.

respondents disagree that simple footwear are adequately provided to the workers as is also evidencedin Figure 3 , which signifies limited commitment of their employers in safeguarding the safety of their employees. This could also expose the workers to be vulnerable to puncture wounds which could be complicated by tetanus.

Table 6: Responses from respondents on personal protective equipment based on percentages (\%).

\begin{tabular}{|l|l|l|l|l|l|l|}
\hline Personal protective equipment & \multicolumn{1}{|c|}{$\mathrm{S} / \mathrm{A}$} & \multicolumn{1}{|c|}{$\mathrm{A}$} & $\mathrm{N}$ & $\mathrm{D} / \mathrm{D}$ \\
\hline $\begin{array}{l}\text { Enough hand gloves are provided } \\
\text { for all workers }\end{array}$ & 6.7 & 6.7 & 10.0 & 66.7 & 10.0 \\
\hline $\begin{array}{l}\text { Foot wear is provided for all the } \\
\text { workers }\end{array}$ & $\mathrm{Nil}$ & 10.0 & 16.7 & 60.0 & 13.3 \\
\hline $\begin{array}{l}\text { The right weatherproof clothing is } \\
\text { provided }\end{array}$ & 6.7 & 6.7 & 10.0 & 73.3 & 3.3 & 100 \\
\hline $\begin{array}{l}\text { Reinforced trousers are used to } \\
\text { minimize against puncture wounds }\end{array}$ & 3.3 & 30.0 & 16.7 & 40.0 & 10.0 \\
\hline $\begin{array}{l}\text { Nose masks are provided for all the } \\
\text { workers }\end{array}$ & 6.7 & 6.7 & 10.0 & 70.0 & 6.7 \\
\hline
\end{tabular}


Possible Health Danger Associated With Gabbage/Refuse Collectors

\begin{tabular}{|l|l|l|l|l|l|l|}
\hline $\begin{array}{l}\text { Enough high visibility clothing is } \\
\text { provided for all workers }\end{array}$ & 3.3 & 16.7 & 16.7 & 56.7 & 6.7 & 100 \\
\hline $\begin{array}{l}\text { Personal protective equipment are } \\
\text { always tried out before general use }\end{array}$ & 6.7 & 6.7 & 3.3 & 63.3 & 20.0 & 100 \\
\hline $\begin{array}{l}\text { Workers always make use of their } \\
\text { protective material at work }\end{array}$ & 3.3 & 30.0 & 10.0 & 53.3 & 3.3 & 100 \\
\hline
\end{tabular}

*S/A-Strongly Agree A-Agree N-Neutral D-Disagree S/D-Strongly Disagree

Ten percent of the respondents agree that footwear were provided for all the workers, $16.7 \%$ are neutral and $60 \%$ disagree and $13.3 \%$ strongly disagree. The majority of

One respondent representing 3.3\% strongly disagreed that right weather appropriate clothingis provided; twenty-two representing $73.3 \%$ disagree. The aggregate respondents that disagreed stood at $76.6 \%$ which indicated that welfare of the workers is not a priority to their employers. This negative attitude justifies the reason why all the workers are foreigners that have no option in selecting the type of job they can do to earn a living. Three of the respondents are neutral, two representing $6.7 \%$ agree and another two representing $6.7 \%$ strongly agree.

Ten percent of the respondents strongly disagree that reinforced trousers are used to minimize against puncture wounds, $40 \%$ disagree. Workers were therefore vulnerable to puncture wounds which could be complicated by tetanus. While $16.7 \%$ are neutral, $30 \%$ agree and 3.3\% strongly agree and this is because even those that agree are using their personal trousers by wearing two or three trousers while on duty, but these have never been provided by their employers including those working with the different contractor at Putrajaya which is contrary to the Malaysian OSHA, 2006.

Only $6.7 \%$ of the respondents strongly disagreed that nose marks are provided for all the workers while $70 \%$ disagree. Meanwhile, $76.7 \%$ of respondents disagree that nose mask is adequately distributed to them for efficient conduct of their work. A nose mask has a number of advantages to waste collectors, because it would ensure protection against obnoxious smells and inhalation of various toxic pollutants. $10 \%$ of the respondents are neutral, $6.7 \%$ agree and $6.7 \%$ strongly agree bringing the total percentage of those that strongly agree and agree to $13.4 \%$.

$6.7 \%$ of the respondents strongly disagree that enough high visibility clothing for all workers is provided, $56.7 \%$ disagree. The workers at work could not be sighted from afar thus could possibly be knocked down by oncoming vehicles. $16.7 \%$ are neutral while $16.7 \%$ strongly agrees and $3.3 \%$ agree.

$20 \%$ of the respondents strongly disagree that personal protective equipment are always tried out before general use. $63.3 \%$ disagree bringing the total percentage of those strongly disagree and disagree to $(83.3 \%)$. This is because it was rare to find workers in their complete outfit at work contrary to the ideal situation. $3.3 \%$ are neutral while $6.7 \%$ agree and another $6.7 \%$ strongly disagree

$53.3 \%$ of the respondents disagree that workers always make use of their protective material at work, $3.3 \%$ strongly disagree while $10 \%$ are neutral and $30 \%$ agree and $3.3 \%$ strongly agree. This brings the percentage of those who disagree and strongly disagree to $56.6 \%$; this is because it was very rare to find workers in their complete outfit at work as evidenced in pic 2 below, contrary to the ideal situation. Incidentally working with suitable protective equipment's is the only condition that can reduce the hazards of the job to a minimum. The practices of not using personal protective equipment at all times were contrary to the 2006 Malaysian OSHA.

Table 7: Prevalence of musculoskeletal disorders

\begin{tabular}{|l|l|l|l|l|}
\hline \multirow{2}{*}{ Prevalence of present musculoskeletal disorder } & Agree & \multicolumn{2}{|c|}{ Neutral } & \multicolumn{2}{|c|}{ Disagree } \\
\hline Neck & 23.3 & Nil & 76.7 & 100 \\
\hline Shoulders & 53.3 & Nil & 46.7 & 100 \\
\hline Elbow & 40.0 & Nil & 60.0 & 100 \\
\hline Wrists / Hand & 50.0 & Nil & 50.0 & 100 \\
\hline Hips / Thighs & 40 & Nil & 60.0 & 100 \\
\hline Low back & 60.0 & Nil & 40.0 & 100 \\
\hline Upper back & 53.3 & Nil & 46.7 & 100 \\
\hline Ankles / Feet & 36.7 & Nil & 63.3 & 100 \\
\hline Knees & 36.7 & Nil & 63.3 & 100 \\
\hline
\end{tabular}

The distribution of musculoskeletal complaints among waste collectors showed that $23.3 \%$ of the respondent agree or complain that the neck is one of the most prevalentlocations of musculoskeletal disorders while $76.7 \%$ disagree simply because the waste collectors are not using their head for the collection or transportation of the waste, while $46.7 \%$ disagree that shoulders are a prevalentlocation of musculoskeletal disorders and $53.3 \%$ agree due to the fact that the waste collectors are always using their strength for lifting the 
waste from plastic bags, waste bin and two wheel containers to the waste collection vehicle which have a direct effect on the shoulders as shown in Figure $2 \& 3$ below

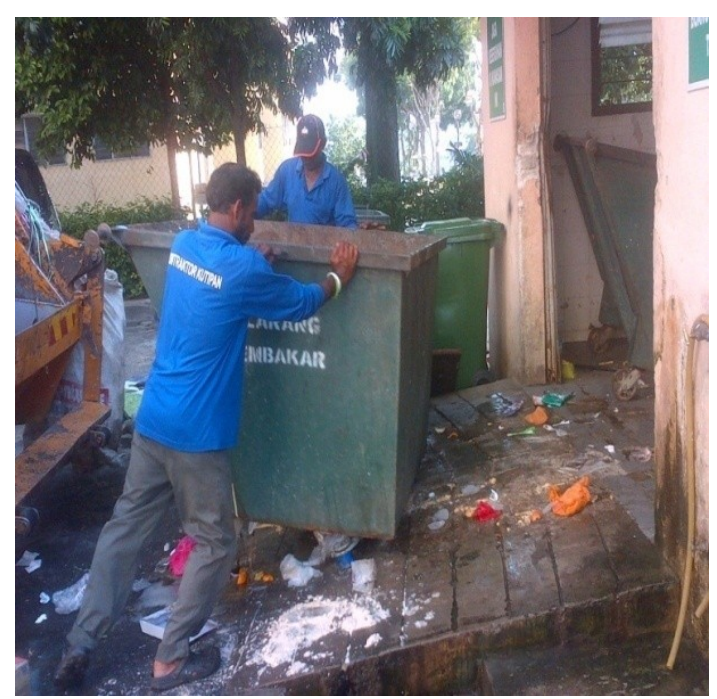

Figure2.Refuse collectors are manually moving the heavy four-wheeled container

The above Figure testifies the answers given by the respondents as waste collection was conducted manually and poses a serious threat of sustaining musculoskeletal injuries, especially in the shoulders and wrist as considerable pressure were exerted on them while collecting municipal waste.

$40 \%$ of the respondents agree or complain that the elbow is a prevalent location of musculoskeletal disorders while $60 \%$ disagree. This is evidenced by constantly moving their hands while bending and stretching their elbow, which over time produces musculoskeletal disorders. $50 \%$ of the total respondents disagree that the wrist/hand is a prevalentlocation for musculoskeletal disorders, while another $50 \%$ agree. This is due to the fact that while collecting the large volume of waste they always graft and lift the waste containers using their hands and at the same time transporting it to the waste collection vehicle using hand as a medium which makes it one of the vulnerable parts for musculoskeletal disorder, contrary to when hydraulic lifts are used (California occupational guide, 2002).

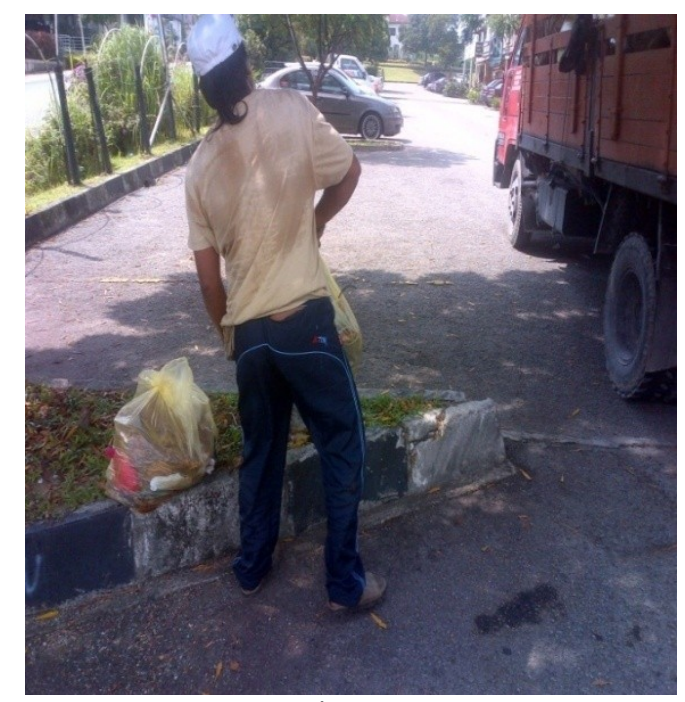

Figure:

$60 \%$ of the respondent disagree that hips/thighs are a prevalent location of musculoskeletal disorders while $40 \%$ disagree, which is as a result of their constant movement while collecting waste.

$40 \%$ of the respondent disagree that the lower back is one of the prevalent locations for musculoskeletal disorders while $60 \%$ agree which is caused by their constant bending and straightening their body while picking up the waste containers and also by lifting the heavy weight containers. This also brings $46.7 \%$ of the respondents to disagree that the upper back is a prevalent location for musculoskeletal disorders while $53.3 \%$ 
agree or complain of upper back pain due to constant movement of their body by bending and straightening their body while picking waste containers and this are in line with the assertion of Yang et al.(2001) that the risks for musculoskeletal complaints of the lower back and upper back among refuse collectors were more than two times higher than those of their colleagues that worked in the office.

$63.3 \%$ of the respondents disagreed that ankle/feet are some of the prevalent locations for musculoskeletal disorders while $36.7 \%$ complained of ankle/feet as one of their musculoskeletal disorder because of their regular movement on the ground which cover some kilometers while collecting waste containers and $63.3 \%$ disagree that the knees is one of the prevalent locations of musculoskeletal disorder while $36.7 \%$ agree or complain of knee problems.

$30 \%$ of the respondents disagreed that puncture by sharp object on hand is one of the prevalent injury locations while $70 \%$ complain of puncture by a sharp object on the hand as a prevalent injury due to none usage of hand gloves while collecting wasteand $40 \%$ of the respondents disagree that puncture by a sharp object on the leg is one of the prevalent injuries while $60 \%$ agree and this corroborates the submission of Inyang M. (2007) that sustaining of injuries from sharp objects is expected from waste collectors since they do not always use protective equipment at work.

$43.3 \%$ of the respondents disagree that puncture woundsto the body by sharp objects is a prevalent injury while $56.7 \%$ complain of puncture woundsto the body due tonon-use of thick clothing while on duty. $23.3 \%$ of the respondents disagree that cutsto the hand by broken bottle/glass is a cause of injury during waste collection while $76.7 \%$ complain of cutsto their hand due to non-use of hand gloves and this corroborates with the submission of Bogale et al.(2014) that hands were the most injured body parts and cuts were the most common injury type waste collectors were exposed to while on duty.

Table 8: Prevalentbody locations that frequently sustain injuries

\begin{tabular}{|l|l|l|l|}
\hline Prevalent location of injuries & Agree & Neutral & Disagree \\
\hline Puncture by sharp object on hand & 70.0 & Nil & 30.0 \\
\hline Puncture by sharp object on leg & 60.0 & Nil & 40.0 \\
\hline Puncture by sharp object on body & 56.7 & Nil & 43.3 \\
\hline Cut on hand by broken bottle/glass & 76.7 & Nil & 23.3 \\
\hline Cut on leg by broken bottle/glass & 70.0 & Nil & 30.0 \\
\hline $\begin{array}{l}\text { Scrapes and bruises on leg due to falls or slips while } \\
\text { dismounting from the truck }\end{array}$ & 60.0 & 40.0 \\
\hline
\end{tabular}

$30 \%$ of the total population disagree that cuts to the leg by broken bottle/glass are prevalent injuries and $70 \%$ accept they are due to not usingprotective footwear or any protective equipment on their legs.

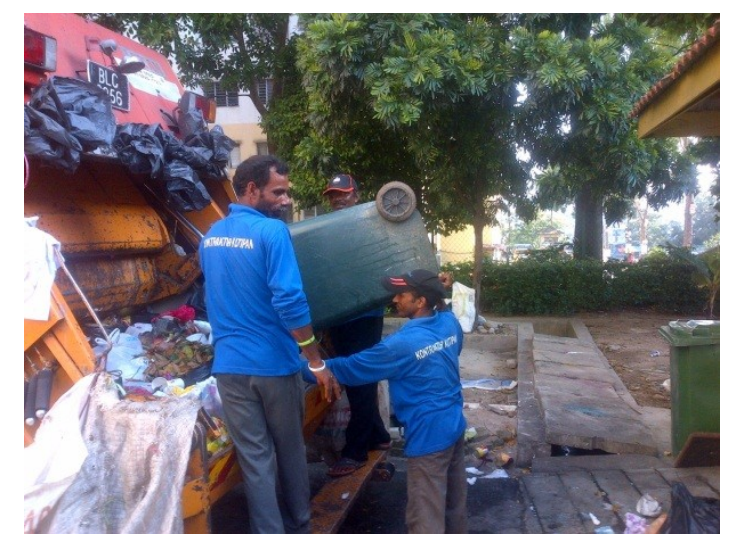

Figure 3: Showing refuse collector while performing their task without any safety equipment

The evident from the above Figure that municipal waste collectors are not using any protective wear to protect themselves from the dangers of their job. The waste collectors, as can be seen, are not wearing any mask, hand gloves, or footwear while $40 \%$ disagree that scrapes and bruises to the leg are due to falls or slips while dismounting from the truck and $60 \%$ agree. This is because workers are not using appropriate footwear and thick clothing while on duty which is contrary to Malaysian OSHA 2006.

\section{Conclusion}

Solid waste collectors in municipalities experience different types of preventable health dangers inherent in their jobs due to their work practice. The health danger they experience range from injuries of all kinds and musculoskeletal pains. Finding of the study revealed that they were not given adequate protective 
equipment to work with and those given were not using it always to ensure their safety which is contrary to OSHA 2006 requirement. The workers were not monitored to ensure they used their protective equipment.

Findings of the study necessitated such recommendations as the provision of trucks with hydraulic lifts for packing of the refuse to ease the job for the collectors and also reduce the incidence of musculoskeletal pains. Quality protective materials appropriate to the task should be provided. The waste collector should be educated on the importance of using safety wear and also monitored with penalties attached to ensure compliance. Safety representatives should be engaged to ensure that all the safety measures are observed in the course of discharging these duties. Refuse collectors should compulsorily undergo periodic health surveillance since specific occupational demands are still present in their jobs. The health surveillance will help in detecting early signs of disease and monitor their ability to work.

Until the above preventive measures are adopted and implemented the solid waste collectors will continue to be at risk of various health danger associated with the job.

\section{References}

[1]. Abou-Elwafa HS, El-Bestar SF, El-Gilany A-H, et al, Musculoskeletal disorders among municipal solid waste collectors in Mansoura, Egypt: a cross-sectional study, BMJ Open 2012;2:e01338.

[2]. Daniel Bogale, AberaKumie and WorkuTefera: Assessment of occupational injuries among Addis Ababa city municipal solid waste collectors: a cross-sectional study. BMC Public Health 2014 14:169

[3]. California Occupational Guide Number 460 (2002).File://E:/Refuse collectors.1 htm.Retrieved on 13 March 2014.

[4]. IJzelenberg W, Molenaar D, Burdorf A. Different risk factors for musculoskeletal complaints and musculoskeletal sickness absence. Scand J Work Environ Health 2004;30:56-63.

[5]. Inyang M. Health and safety risks amongst the municipal solid waste collectors in Port Harcourt Metropolis of the Niger Delta Region of Nigeria. International Conference "Waste Management, Environmental Geotechnology and Global Sustainable Development (Icwmeggsd'07-Gzo'07)” Ljubljana, Slovenia, August 28-30, 2007.

[6]. Kuijer P, Frings-Dresen M, de Looze M, et al. Work situation and physical workload of refuse collectors in three different time periods. Int J IndErgon 2000; 26:509-19.

[7]. Kuijer P, Frings-Dresen M. World at work: refuse collectors. Occup Environ Med 2004;61:282-6.

[8]. Kuijer P, Sluiter J, Frings-Dresen M. Health and safety in waste collection: towards evidence-based worker health surveillance. Am J Ind Med 2010; 53:1040-64. .

[9]. Law of Malaysia (2006). Occupational safety and health act 1994: The commissioner of law revision Malaysia. P. 20-22.

[10]. Lincoln J: Injuries Associated with Refuse collectors and landfill workers in Anchorage. Alaska; 1996: 177-80.

[11]. Merson MH, Black RE, Mills AJ, International Public Health: Diseases, Programs, Systems and Policies. Gaithersburg, Maryland: Aspen Publishers; 2001.

[12]. Paulsen OM, BreumNO,Ebbehoj $\mathrm{N}$ et al. Collection of domestic waste. Review of occupational health problems and their possible causes. Sci Total Environ 1995;170: 1-19.

[13]. Ray MR, Roy Choudhury S, Mukherjee G, Roy S, Lahiri T. Respiratory and general health impairments of workers employed in a municipal solid waste disposal at an open landfill site in Delhi. Int J Hyg Environ Health 2005; 208:255-262.

[14]. Sabde YD, Zodpey SP: A study of morbidity pattern in street sweepers: a cross-sectional study. Indian J Community Med 2008, 33(4).

[15]. Tiwari RR: Occupational health hazards in sewage and sanitary workers Indian. J Occup Environ Med 2008, 12(3):112-115.

[16]. Wouters I, Hilhorst S, Kleppe P, et al. Upper airway inflammation and respiratory symptoms in domestic waste collectors. Occup Environ Med 2002; 59:106-12.

[17]. Yang C, Chang W, Chuang H, et al. Adverse health effects among household waste collectors in Taiwan. Environ Res 2001; $85: 195-9$. 